\title{
Benign-by-design advanced nanomaterials for environmental and energy-related applications Maurizio Selva ${ }^{1,2}$ and Rafael Luque ${ }^{2,3}$
}

This contribution aims to disclose recent advances and key benign-by-design systems for a number of environmental and energy-related applications.

\author{
Addresses \\ ${ }^{1}$ Dipartimento di Scienze Molecolari e Nanosistemi Dell'Universitá Ca- \\ Foscari di Venezia, Via Torino 155, 30175, Venezia-Mestre, Italy \\ ${ }^{2}$ Departamento de Quimica Organica, Universidad de Cordoba, \\ Campus de Rabanales, Edificio Marie Curie (C-3), Ctra Nnal IV-A, Km. \\ 396 E-14014, Cordoba, Spain \\ ${ }^{3}$ Peoples Friendship University of Russia (RUDN University), 6 \\ Miklukho-Maklaya Str., 117198, Moscow, Russia
}

Corresponding author: Luque, Rafael (q62alsor@uco.es)

Current Opinion in Green and Sustainable Chemistry 2019, 15:98-102

This review comes from a themed issue on Selected papers from the 3rd Green and Sustainable Chemistry Conference 2018

Edited by Klaus Kümmerer and Zhimin Liu

https://doi.org/10.1016/j.cogsc.2018.12.007

2452-2236/@ 2018 Elsevier B.V. All rights reserved.

Society is facing significant daunting challenges in the 21 st century, mostly related to the availability of resources, climate change, energy demands, water supply, and efficiency of processes for a more sustainable development. The future generations will have to address those issues through a multidisciplinary approach encompassing disciplines including (bio) chemistry, materials science, and engineering in an unprecedented coordinated monitoring and modeling of many factors, from social to economic, and environmental standpoints [1,2]. This major task will be possible only by a multistakeholder global strategy involving not only natural and social scientists and engineers but also the industrial world, the civil society, and governments.

Advances in (nano)materials' design and engineering will pave the way to innovative systems that will combine improved efficiencies to maximize the use of resources and performance (as compared to current productions) with biocompatibility and environmentally soundness. This is essentially the benign-by-design concept applied to the design of novel functional

Dedicated to Dr. Rajender S. Varma, colleague and dear friend, for his inspiration and leadership in the field over the past decades. materials as a paradigm for a more sustainable supply and production of chemicals and energy (Figure 1).

A number of recent advances in the field of heterogeneous photocatalysis, biocatalysis, electrocatalysis, and environmental catalysis have significantly contributed to set the key milestones for the future. These include applications in catalysis, energy conversion and storage, and environmental remediation. In this respect, extensive research efforts have been addressed to cope with issues to secure clean and sustainable water supply [4], and a remarkably simple solution for electrocatalytic mineralization of pollutants (e.g. microcystins) from wastewater has been recently achieved using sustainable electrode materials based on cheap commercial graphite cylindric bar-supported titania anodes [5].

Most current strategies to fabricate potential electrocatalysts usually require hazardous and expensive precursors, external heteroatom-containing compounds, and additional templates and chemicals, which clearly give rises to costs and limit their economic applications [6]. To overcome these drawbacks, the conversion of natural resources into carbon-based materials or the modification of cheap commercial graphite is opening new horizons as effective strategies to engineer more sustainable materials with advanced electrocatalytic properties.

In a recent work, graphite carbon cylinders $(3 \mathrm{~cm} \times \varnothing$ $2 \mathrm{~mm}$; c.a. $1.2 \mathrm{~g}$ ) from cheap commercial pencils were used as based anode upon convenient and effective modification with nanosized titanium oxide nanoparticles $\left(\mathrm{TiO}_{2} @\right.$ Carbon) via microwave-assisted deposition at moderate temperatures (ca. $120{ }^{\circ} \mathrm{C}$ ). The synthesized anode was used in the remediation of nodularin cyanotoxin, both under defined media conditions ( $\mathrm{NaCl} 10 \mathrm{mmol} \mathrm{L}^{-1}$ ) as well as most importantly tap water, for which a quantitative degradation of the cyanotoxin was achieved within 20-60 min (Figure 2).

Several advantages of the proposed electrocatalytic method include (1) the control of processes by the potential at electrode/electrolyte interfaces for complete mineralization; (2) versatility and applicability to a wide range of wastewaters containing varying pollutants in different concentrations; and (3) cost-effectiveness, simplicity, compactness, and robustness with potential for scale-up applications. 


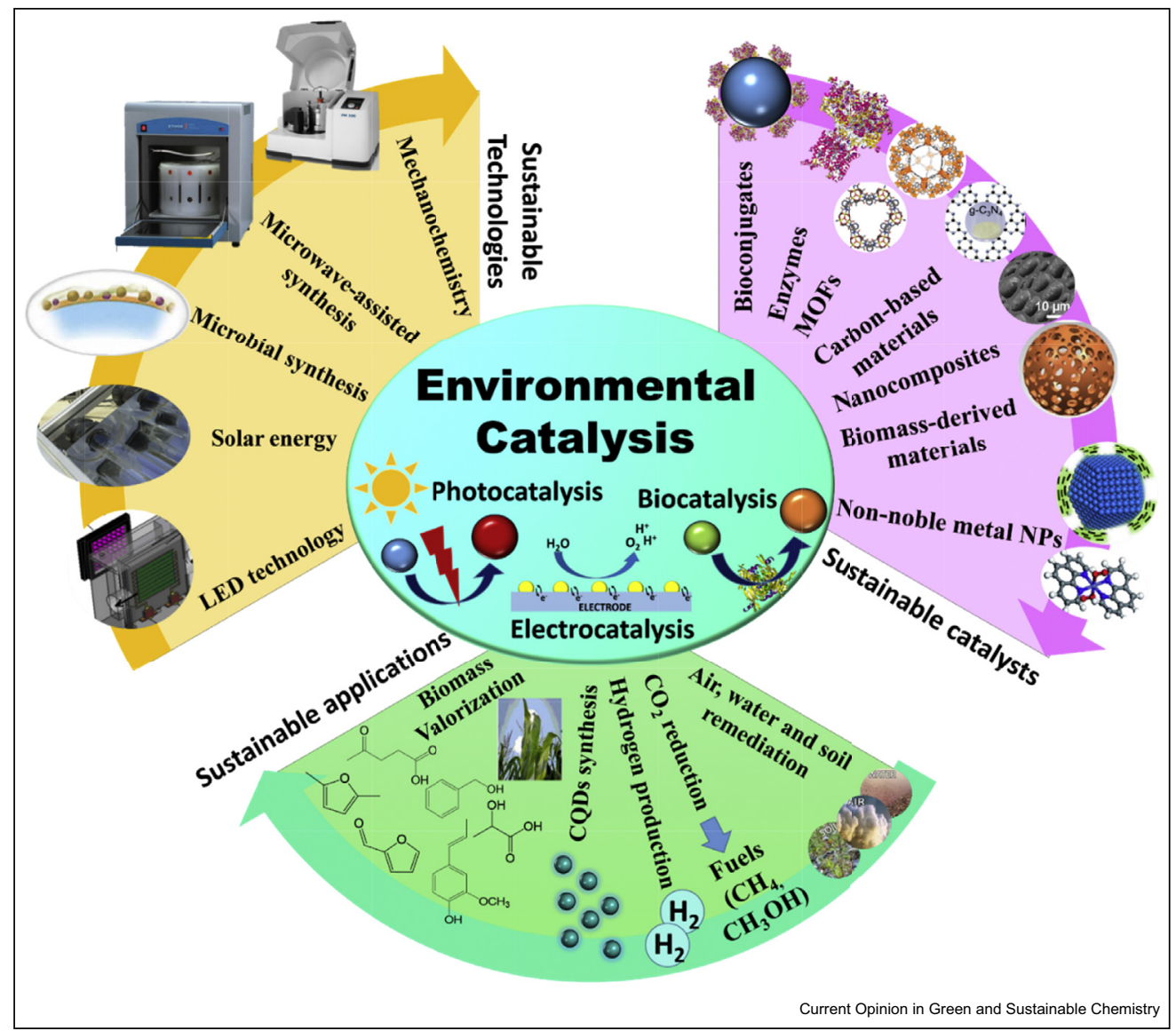

Benign-by-design technologies for the design of sustainable materials for relevant future applications. Light emitting devices (LED), Carbon Quantum Dots (CQD), nanoparticles (NP) and Metal Organic Franeworks (MOF).

\section{Figure 2}

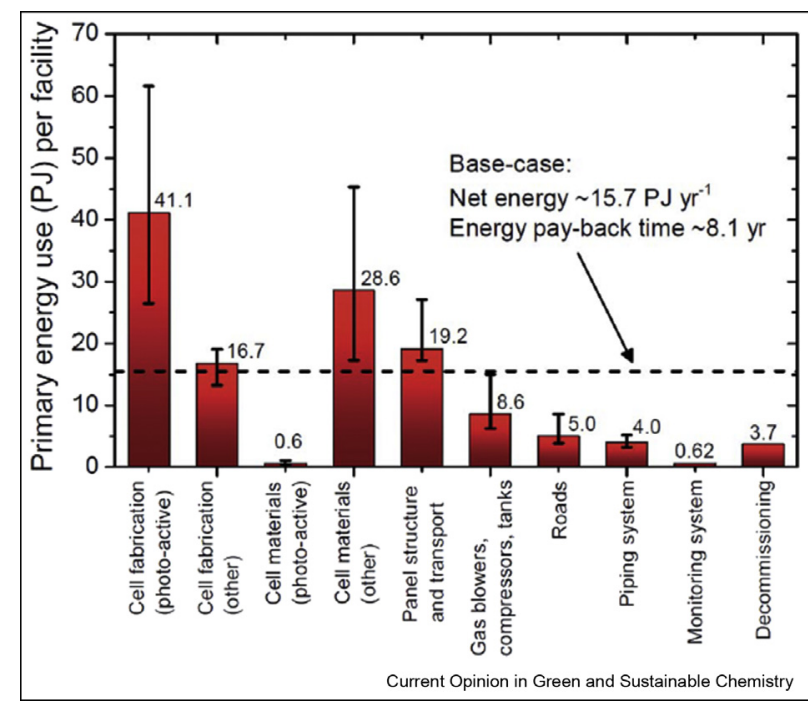

Life-cycle net energy assessment of large-scale hydrogen production via photoelectrochemical water splitting. Reproduced by permission of the Royal Society of Chemistry from reference 14.
Photoelectrocatalysis, commonly defined as a type of catalysis that results in the modification of electrochemical reaction rates at the electrode/electrolyte interfaces via light irradiation, has also recently emerged as a useful tool toward energy production [7-9]. Importantly, the development of environmentally friendly strategies toward the synthesis of benign-bydesign (photo)electrocatalysts has captured the attention of the scientific community in the last few years because of the ever-increasing demand for sustainable conversion and storage of renewable energy.

In this regard, photoelectrochemical (PEC) reactions have to date been reported to efficiently afford both the generation of hydrogen from water and the (photo) electroreduction of $\mathrm{CO}_{2}$ to produce carbon-based fuels from renewable resources. Following seminal reports in literature [10] and several important overviews in the field $[11,12]$, an elegant recent approach on scalable water-splitting photocatalysts has described a solar-tohydrogen energy conversion efficiency exceeding $1.1 \%$ using $\mathrm{La}$ - and $\mathrm{Rh}$-codoped $\mathrm{SrTiO}_{3}\left(\mathrm{SrTiO}_{3}: \mathrm{La}, \mathrm{Rh}\right)$ and 
Mo-doped $\mathrm{BiVO}_{4}\left(\mathrm{BiVO}_{4}: \mathrm{Mo}\right)$ powders embedded into a gold $\mathrm{(Au})$ layer [13]. A remarkable enhancement of the electron relay could be achieved by annealing and suppression of undesirable reactions through surface modification to allow pure water ( $\mathrm{pH}$ 6.8) splitting to hydrogen with an apparent quantum yield of more than $30 \%$ at $419 \mathrm{~nm}$. The proposed system allowed the fabrication of scalable water-splitting devices using particulate semiconductors, certainly most useful to pave the way to future hydrogen production designs.

The most interesting information toward the assessment of large-scale production of such PEC systems was also present [14] to back up the recent reported work by Domen et al. [13]. In these studies, a life-cycle net energy assessment of a hypothetical large-scale PEC hydrogen production facility with energy output equivalent to $1 \mathrm{GW}$ continuous annual average (1 GW $\mathrm{HHV}=610$ metric tons of $\mathrm{H}_{2}$ per day) was provided. Based on a number of premises, the energy payback time was 8.1 years, the energy return on energy invested was 1.7 , and the life-cycle primary energy balance over the 40 years projected service life of the facility is +500 PJ under base-case conditions. The most important model parameters affecting the net energy metrics were the solar-to-hydrogen conversion efficiency and the life span of the PEC cells. Other parameters associated with the balance of systems, including construction and operation of the liquid- and gas-handling infrastructure, were found to play a minor role, providing guidelines for the application of the model system to PEC and photochemical devices in the future.
The (photo)electrochemical reduction of $\mathrm{CO}_{2}$ to valuable chemicals including $\mathrm{CO}, \mathrm{CH}_{4}$, and alcohols has also attracted a great deal of interest, covered by a couple of recent contributions in the field $[15,16]$. An inventive approach to investigate the products distribution during the electrochemical reduction of carbon dioxide has been recently proposed by an advanced analytical method, making use of differential electrochemical mass spectrometry [17]. The coating of the electrocatalyst $(\mathrm{Ag}$ and $\mathrm{Cu})$ on a pervaporation membrane enabled the sampling and characterization of species released close to electrode-electrolyte interface, thereby allowing to measure not only the intrinsic kinetic of the $\mathrm{CO}_{2}$ reduction but also the relative abundance of aldehyde and alcohol products near the cathode surface. Hypothesis on the mechanism and reaction intermediates was so formulated.

Another remarkable procedure described the photoreduction $\mathrm{CO}_{2}$ in a dual-chamber reactor equipped with a multicomponent catalyst comprised of $\mathrm{Cu}_{2} \mathrm{O}$, graphene and an array of $\mathrm{TiO}_{2}$ nanotubes [18]. Graphene played multiple roles by protecting $\mathrm{Cu}_{2} \mathrm{O}$ against photocorrosion, promoting charge separation and electronic transfer across the heterojunction interfaces, and preventing backward reactions. Moreover, the high electron density of graphene enhanced the selectivity for the multielectron reduction of $\mathrm{CO}_{2}$ to methanol which was generated at a rate of $45 \mu \mathrm{mol} \mathrm{cm}{ }^{-2} \mathrm{~h}^{-1}$. At $420 \mathrm{~nm}$, the corresponding quantum efficiency was $5.71 \%[18]$.

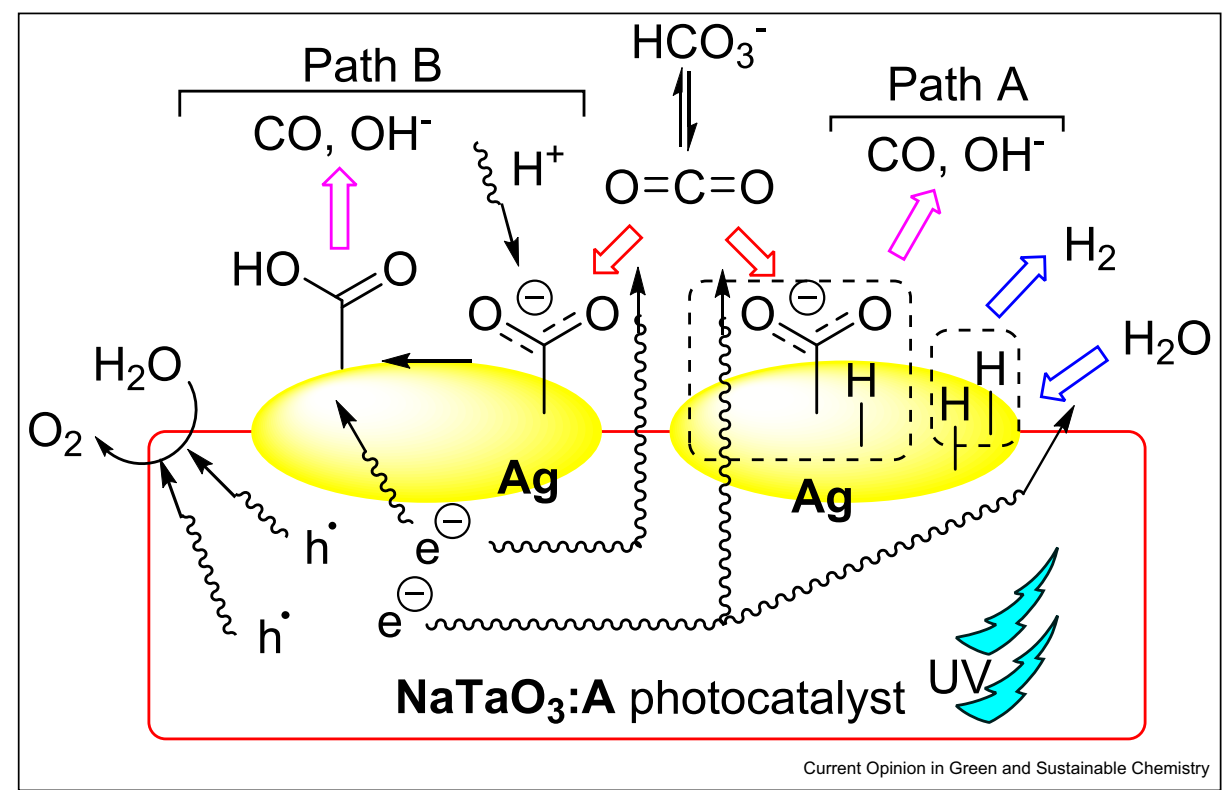

Photoreduction of $\mathrm{CO}_{2}$ catalyzed by mixed oxides in the presence of water using a Ag-based cocatalyst. Copyright Wiley-Verlag VCH. Reproduced with permission. 
Last, but not least, $\mathrm{CO}_{2}$ photoreduction was also reported using a catalyst based on a A-doped $\mathrm{NaTaO}_{3}$ $(\mathrm{A}=\mathrm{Mg}, \mathrm{Ca}, \mathrm{Sr}, \mathrm{Ba}$, or $\mathrm{La})$ in the presence of water as electron donor and an Ag cocatalyst (Figure 3) [19].

The conduction band level of A-doped $\mathrm{NaTaO}_{3}$ allowed photogenerated electrons on the surface of $\mathrm{Ag}$ cocatalyst, potential of which was high enough for the reduction of both $\mathrm{CO}_{2}$ to $\mathrm{CO}$ and $\mathrm{H}_{2} \mathrm{O}$ to $\mathrm{H}_{2}$, according to paths a) and b). Notably, the selectivity for the formation of $\mathrm{CO}$ has been around $90 \%$, with an activity in the range of $88-176 \mu \mathrm{mol} \mathrm{CO} \mathrm{h}^{-1}$ [19].

\section{Conclusions and prospects}

Promising methodologies and novel technologies for the environmentally friendly design of catalytic systems, as well as emerging materials with low toxicity and costs and performances for environmental catalysis, will be part of the future in the field. Special attention should be paid to protocols including mechanochemistry, microwave-assisted and photo (electro)chemical processes for catalyst design, and derived sustainable uses.

Photocatalysis and electrocatalysis have been considered because of their applicability in crucial processes to solve environment-related problems. Methods for artificial photosynthesis and photo (electrochemical) conversion including water splitting and $\mathrm{CO}_{2}$ reduction have an enormous potential, most of it remaining to be disclosed yet. From the economic standpoint, a challenge in the coming decades for the future of photo (electro) reduction methods must also focus on point sources of $\mathrm{CO}_{2}$ because the current capturing from air (where the average concentration is of only $400 \mathrm{ppm}$ ) still shows uncompetitive high costs of approximately $500 €$ per tonne of captured $\mathrm{CO}_{2}[20]$.

Additional emerging trends and topics will relate to the combination of photocatalytic and thermocatalytic effects to enhance catalytic performance combined with the use of sunlight as already demonstrated in the literature $[21,22]$ including, for example, $\mathrm{H}_{2}$ photoproduction [23], and fuels production from $\mathrm{CO}_{2}[22,24]$. Future strategies in electrocatalysis also include the use of renewable sources such as wind and solar to obtain renewably generated electricity.

Besides advances in environmental catalysis achieved so far at the laboratory scale, ways must be sought to integrate such results to the needs of industry through scale-up analysis of sustainable catalytic materials and processes. We hope that the key emerging topics and contributions summarized in this work may inspire the scientific community to move toward benign-by-design materials and processes for a more sustainable future.

\section{Acknowledgements}

R.L. gratefully acknowledges funding from MINECO under Project CTQ2016-78289-P, co-financed with FEDER funds. M.S. gratefully acknowledges support from Universita Ca' Foscari for a sabbatical stay at group FQM-383 from Universidad de Cordoba. The publication has been prepared with support from RUDN University Program 5-100.

\section{References}

Papers of particular interest, published within the period of review, have been highlighted as:

* of special interest

** of outstanding interest

1. Garcia-Martinez: J Chem Int 2016. https://www.degruyter.com/ downloadpdf/j/ci.2016.38.issue-3-4/ci-2016-3-405/ci-2016-3-405. pdf.

2. Lu Y, Nakicenovic N, Visbeck M, Stevance AS: Nature 2015, 520 432-433.

4. Anjum M, Miandad R, Waqas M, Gehany F, Barakat MA: Arabian J Chem 2016. https://www.sciencedirect.com/science/article/pii/ S1878535216301757.

The authors provide a very detailed overview of the technologies and possibilities for water purification.

5. Ferreira Garcia L, Sanz G, Gonçalves Costa G, Yepez A, Rodri** gues Siqueira AC, Rodrigues de Oliveira GA, Luque R, de Souza Gil E: ACS Sustainable Chem Eng 2019. https://doi.org/10.1021/ acssuschemeng.8b04956.

Using a simple and cheap modified graphite electrode and an electrochemical method, cyanotoxins (Nodularin) could be completely degraded from wastewater.

6. Zhang W, Zhu S, Luque R, Han S, Hua L, Xu G: Chem Soc Rev 2016, 45:715-752.

7. Asefa T: Acc Chem Res 2016, 49:1873-1883.

8. Borghei M, Lehtonen J, Liu L, Rojas OJ: Adv Mater 2018, 30: ** 1703691

An excellent overview in recent progress in advanced nanostructures synthesized from biomass resources for the oxygen reduction reaction (ORR) is provided.

9. You B, Sun Y: Acc Chem Res 2018, 51:1571-1580.

10. Khaselev O, Turner JA: Science 1998, 280:425-427.

** Seminal work for water splitting for hydrogen production using a monolithic photovoltaic-photoelectroelectrochemical device.

11. Hisatomi T, Kubota J, Domen K: Chem Soc Rev 2014, 43: $7520-7535$.

12. Roger I, Shipman MA, Symes MD: Nature Rev Chem 2017, 1:003.

13. Wang Q, Hisatomi T, Jia Q, Tokudome H, Zhing M, Wang C

** Pan Z, Takata T, Nakabayashi M, Shibata N, Li Y, Sharp ID, Kudo A, Yamada T, Domen K: Nat Mater 2016, 15:611-615.

The first example of photocatalytic water splitting using cheap and environmentally friendly systems with a focus on scalable water splitting devices using particulate semiconductors.

14. Sathre R, Scown CD, Morrow III WR, Stevens JC, Sharp ID, Ager III JW, Walczak K, Houle FA, Greenblatt JB: Energy Environ Sci 2014, 7:3264-3278.

An excellent (and first literature reported) life-cycle net energy assessment study of a hypothetical large-scale photoelectrochemical (PEC) hydrogen production facility.

15. Jia M, Fan Q, Liu S, Qiu J, Sun Z: Current Opin Green Sustain Chem 2019, 16:1-6.

16. Dokania A, Ramirez A, Bavykina A, Gascon J: ACS Energy Lett 2018. https://doi.org/10.1021/acsenergylett.8b01910.

17. Clark EL, Bell AT: J Am Chem Soc 2018, 140:7012-7020. ** An unprecedented study on products distribution during the electrochemical reduction of carbon dioxide using advanced analytical methods (differential electrochemical mass spectrometry).

18. Li F, Zhang L, Tong J, Liu Y, Xu S, Cao Y, Cao S: Nanomater ** Energy 2016, 27:320-329. 
The photoreduction $\mathrm{CO}_{2}$ in a dual-chamber reactor equipped with a multi-component catalyst comprised of $\mathrm{Cu}_{2} \mathrm{O}$, graphene and an array of $\mathrm{TiO}_{2}$ nanotubes was reported to achieve unprecedented methanol rates and quantum efficiencies.

19. Nakanishi H, Lizuka K, Takayama T, Iwase A, Kudo A: ChemSusChem 2017, 10:112-118.

Photoreduction of $\mathrm{CO}_{2}$ catalyzed by mixed oxides in the presence of water using a Ag-based co-catalyst to achieved high selectivties to $\mathrm{CO}$ $(90 \%)$ for further upgrading.

20. Martens JA, Bogaerts A, De Kimpe N, Jacobs PA, Marin GA, Rabaey K, Saeys M, Verhelst S: ChemSusChem 2017, 10 $1039-1055$.

A relevant techno-economic study in which current capturing of $\mathrm{CO}_{2}$ from air for conversion/valorisation shows uncompetitive high costs of approximately (500 $€$ per tonne of captured $\mathrm{CO}_{2}$ ).
21. Muñoz-Batista MJ, Eslava-Castillo AM, Kubacka A, FernándezGarcía M: Appl Catal B Environ 2018, 225:298-306.

22. Fang S, Li Y, Yang Y, Chen J, Liu H, Zhao X: Environ Sci Nano 2017, 4:1798-1807.

23. Docao S, Koirala AR, Kim MG, Hwang IC, Song MK, Yoon KB, Pan Z, Takata T, Nakabayashi M, Shibata N, Li Y, Sharp ID, Kudo A, Yamada T, Domen K, Stobbe P, Jones D, Konstandopoulos AG: Energy Environ Sci 2017, 10:628-640. Photo-thermo catalytic effects for hydrogen production from water splitting

24. Chen G, Gao R, Zhao Y, Li Z, Waterhouse GIN, Shi R, Zhao J, * Zhang M, Shang L, Sheng G, Zhang X, Wen X, Wu L-Z, Tung C$\mathrm{H}$, Zhang T: Adv Mater 2018, 30:1704663.

Photo-thermo catalytic effects for fuels production from $\mathrm{CO}_{2}$. 